\title{
Disaster Vulnerability of Emirati Energy Sector and Barriers to Enhance Resilience
}

Purpose: UAE has experienced various natural and man-made hazards. The energy sector dominates in the UAE and protection of this critical infrastructure against any impending hazards is important. This paper examined the vulnerability of Emirati energy sector, explored barriers to enhance resilience and ways to overcome identified barriers.

Design/methodology/approach: Study followed case study research strategy and multiple case studies; three electricity generating power plant facilities- one in Abu Dhabi, one in Dubai and one in Sharjah were selected. Data collection involved a combination of a questionnaire survey and semistructured face-to-face interviews. In total 42 questionnaire responses and 9 interviews among Emirati energy sector employees were analysed.

Findings: Results indicated terrorism, atmospheric and tectonic hazards as the three main risks of vulnerability within Emirati energy sector; whereas 'lack of or absence of national government legislation' and 'awareness and education' are revealed as the main barriers. Improving human resource management within Emirati energy sector through better awareness, training and practices is considered as a priority.

Research limitations/implications: It is argued that the vulnerabilities and barriers identified in this study can be applicable to Emirati energy sector in general, not just the case studies represented in the study.

Originality/value: The feedback from the members of the Emirati energy sector is indicative of the latent failures and urgent issues that need to be addressed; predominately those of training, education and awareness. Findings of this study may help UAE energy sector to be prepared and build resilience for future hazards.

Keywords: Disasters, Hazards, Vulnerabilities, Barriers, Energy Sector, UAE

\section{Introduction}

Increasing frequency and intensity of disasters have resulted in severe disruptions to communities and built environment facilities around the world. There is an evident increase in human and property losses from disaster events over the past few decades. In the period between 2000-2011, 2.7 billion people have been affected by disasters, 1.1 million of which were fatalities and the financial cost of disaster impact was estimated at $\$ 1.3$ trillion (UNISDR, 2012). Evidence suggests that disaster risks are rising at a rate faster than affected communities can build resilience (Al Khaili and Pathirage, 2014). Fast growing cities and urban areas of the world increase disaster vulnerability due to economic growth and fast population expansion. Cities, where more than $50 \%$ of the global 
population resides and where much of the economic assets can be found (WHO, 2014), are very much the epicenter for destruction and loss brought about by natural and man-made disasters.

Growing urbanisation results in increased built environment facilities such as buildings and infrastructure, and thus a greater exposure of potential human populations and services to natural or man-made hazards (Gonzalez-Diez et al., 2012). The need to address disaster vulnerability of built environment facilities such as infrastructure is becoming increasingly important. How these facilities are designed and built, and where they are located, is critical to their ability to withstand different types of natural or man-made hazards. The energy sector is a strategic component of any modern society. As the demand for electricity and energy grows, so do the complexity of the system and the need to protect it. The significant increase in consumer demand and population in both developed and developing countries means that not only society dependents upon the energy sector, but also that more people and businesses require an increasing energy supply, in order to operate normally (US EIA, 2013). Failure to protect the energy system and build resilience into the infrastructure could have severe affects, should these assets subjected to a natural or man-made disaster.

The disasters that have frequented the United Arab Emirates (UAE) or at least have the potential to do so, such as storms, earthquakes, tsunamis, terrorist attacks, are complex and diverse in origin as they are in effect. Energy sector dominates in the UAE economy, especially in terms of its production and supply, and holds a very important global position in the world's economy. The protection of these systems and assets and within the energy sector especially, the safeguarding of oil and gas infrastructure from any natural or man-made hazards should become the top priority of the UAE (Al Farra and Abu-Jijleh, 2012). Recent developments in the UAE have progressed towards the concept of disaster resilience. However, preparations for any impending disaster have been slow and in fact, due to the country's recent legal establishment as a nation, disaster preparation has featured on national agenda only very recently. In light of the new nuclear development at Braqa and other expansions in UAE energy sector, it is important to understand vulnerabilities of the sector as a means of preparedness for future natural or man-made hazards. Therefore, this paper explores the vulnerability of Emirati energy sector, examines barriers to enhance resilience and ways to overcome identified barriers. Energy sector covered for this study includes production and distribution of electricity, oil and gas, and comprises of both physical assets and systems. Study will help UAE energy sector to be prepared and build resilience for future hazards.

\section{Disaster Management and Resilience}

Moe et al. (2007, pp 787) define a disaster as "a situation which overwhelms local capacity, necessitating a request to the national and international level for external assistance, or is recognised by a multilateral agency or by at least two sources, such as national, regional or international assistance groups and the media'. Disaster management efforts aim to reduce or avoid the potential losses from hazards, promote prompt and appropriate assistance to victims of disaster, and seek to achieve rapid and effective recovery (Warfield, 2004). Phases in natural disaster management are identified in different terms, which give similar insights. The process of dividing the disaster event into various, albeit overlapping phases and stages is a useful heuristic device driving better 
understanding (Levinson and Granot, 2002) from which a disaster management plan can be implemented. The disaster management cycle includes two main phases of disaster management: predisaster risk reduction and post disaster recovery. Pre-disaster risk reduction involves the identification of potential hazards and vulnerabilities thorough risk assessments, development of forecast and warning systems, modelling and training for a number of disaster scenarios of different hazards and at different magnitudes, development of insurance infrastructure and the growth of an intelligent community (Hays, 2013). Risk and vulnerability assessment is one of the important stages within pre-disaster risk reduction phase. It involves identifying the nature and magnitude of current and future risks from hazards to people, infrastructure and buildings (RICS, 2009; McEntire, 2010). Through vulnerability analysis it is possible to identify which public and private buildings and infrastructure should be reinforced or relocated and which infrastructure needs risk reduction measures. The ultimate goal of disaster management is to break the disaster life cycle (Frumkin, 2010).

Mitigation or risk reduction activities include structural and non-structural measures undertaken to limit the adverse impact of natural hazards, environmental degradation and technological hazards (Atmanand, 2003). Preparedness deals with the activities and measures taken in advance to ensure an effective response to the impact of hazards, including the issuance of timely and effective early warnings and the temporary evacuation of people and property from threatened locations (Atmanand, 2003; Moe et al., 2007). Disaster preparedness is, according to Hays (2013) one of the "five pillars of resilience". Fitzgerland and Fitzgerald, (2005: p5) define disaster resilience as 'the ability of social units (e.g. organisations, communities) to mitigate hazards, contain the effects of disasters when they occur, and carry out recovery activities in ways that minimise social disruption and mitigate the effects of future disasters'. In this way, pre-disaster risk reduction phase is guided in a manner that adequately protects social units through risk analysis and preparedness (Ciottone, 2006). As such this study focused on risk and vulnerability assessment of Emirati energy sector in view of building resilience for future hazards. Following section describes disasters experienced by the UAE.

\section{United Arab Emirates and Disasters}

The Emirates and its archipelago that extends over the Arabian Gulf cover 83,600 sq km. The Emirati coastline extends for approximately $700 \mathrm{~km}$. The country shares land borders with Qatar to the west, Saudi Arabia to the south and west, and Oman to the east and south. Four-fifths of the UAE's land mass is desert. The littoral zone of the UAE is characterised by active coastal 'sabkhas', a phonetic translation of the Arabic word for a salt flat (Doherty et al, 2009). In 1980 the total population was 1 million. It increased to 8.4 million only 30 years later. By 2050 the UN expects this figure to reach 15.5 million (EUAEW, 2011). The overwhelming majority of the population lives in urban areas in coastal zones, which is also prone to a number of natural and manmade hazards.

The UAE is prone to various natural hazards including those atmospheric, geological and anthropogenic in origin. There are also meteorological and tectonic hazards to consider. As development continues in the nation the country and its people become even more vulnerable to the effects of those hazards (Al Ghasyah et al 2010). As one might expect rainfall is few and far between. 
Any abnormally high rainfall, which is usually tied to the combination of winter Shamal and atmospheric depressions, makes for headline news. Shamal refers to the abnormal wind that blows in the Gulf region. In November 2013, heavy flooding caused a number of injuries and fatalities when people were swept from their vehicles. Similarly in February 2014, heavy rainfall and unusually cold conditions made headlines with traffic accidents and other property damages (Kazmi 2014). The true impact of the Shamal winds on the coastal region and construction industry were evidenced on 11th January 2005 when the Shamal, combined with a high tide and storm surge, led to wave heights of 4 $\mathrm{m}$ that resulted in fatalities (Gulfnews, 2013). Tectonically, there are 25 seismogenic source zones in the Arabian Peninsula (Al-Amri, 2005) including the Zagros Thrust fault which readily generates earthquakes measuring 5 on the Richter Scale such as the Masafi Earthquake (magnitude $\sim 5$ ). Other potential threats come from the Hurmuz Straits, north of which is one of the most extremely seismic active zones in the world (Shanableh et al, 2005). Most activity has been moderate or minor but there has been a notable increase.

Terrorism presents a key issue that could easily affect the geopolitical stability of the region, if not the entire globe given the number of energy installations, global trade, economy and operations. As of late 2014, 83 organisations are listed in the UAE as terrorist groups (WAM, 2014). Some of them have obvious connections to terrorist activities due to their use of violent and criminal means to dictate their ideology. Obvious examples of this are Islamic State and al Nusra Front (an offshoot of Al-Qaeda). The US also remains concerned about the close proximity of Iran as regards both nuclear and terrorist activity (Katzman, 2012). It also associates the UAE's large expatriate population, with a potential increase in terrorist activities, given that there have been incidents and terrorist groups in their native countries, which could have an impact on Emirati national security and stability (OSAC, 2013). Therefore, UAE must thus act in a proactive manner and must prepare adequately so that it remains resilient should any disaster event occur.

\section{Emirati Energy Sector and Hazards}

The energy sector dominates in the UAE and the gulf region generally. The Emirati economy is the second biggest regionally after Saudi Arabia and remains on course for five per cent growth protection within the next four years -largely due to rising oil demand (Kazmi 2014). Added to this, 2010 saw the total value of construction contracts awarded in the UAE in the energy sector almost triple to $\$ 8.8$ billion ( $\mathrm{Dh} 32.32 \mathrm{bn}$ ) for the period of January to May, from $\$ 3 \mathrm{bn}$ against the same period in 2009 (Nambier, 2010). The energy sector is therefore very much an economic driver responsible for the positive development of the nation. Some OPEC nations and many non-OPEC nations have seen production decline over the last five years, but the UAE has increased its total production of crude oil by approximately 31 percent and thus plays a highly significant role in global energy markets (EUAEW, 2011). Energy security and supply are equally a priority for a country that has built its reputation as the region's most stable country, both politically and economically with attractive business opportunities that are not found elsewhere (Dalli and Wilcox, 2006). The new development of nuclear power at Braqa, 33 miles from the coast provides another prime reason for addressing disaster risk. The technological choice of Generation III "APR1400", which has enhanced safety features such as longer plant life of 80 years (normally 60 years), enhanced user-friendliness, 
and higher burn-up rates and reduced fuel consumption and waste production (Al Farra and AbuJijleh, 2012) are a few examples of man-made hazards mitigation measures.

It is irresponsible to ignore the UAE's vulnerability to various natural and man-made hazards. The issue of disaster is particularly acute on the coast where the highest population densities, the large number of high-rise buildings and commercial/residential structures are located. Ill-planned urban development has, rather than abated disaster, intensified it. The Arabian Gulf is shallow, about 200 meters or less in most areas and as observed by Hafez and Halim (2007), the terrain is flat, with most of the oil installations either on the shore or in shallow water areas. Major oil fields are either in the shallow area of the gulf or in the desert adjacent to the gulf shores. This makes them vulnerable to large tidal waves or sea storms. In February 2014, for example, Shamal winds helped contribute to unstable cool weather and strong offshore waves that led to warnings. Potential threats to national stability and oil installations stem from regional uprising since the Arab Spring and terrorist activities are also a national concern. This is particularly important in light of the new nuclear development at Braqa. Any form of disruption to the Emirati energy sector is a possibility, given the country's vulnerability to various man-made and natural hazards; however, preparations for any potential disaster have been slow. A national emergency strategy was set-up in 2007 to ensure a prompt coordinated and efficient response to any potential disaster (Al Kindi, 2007). This is particularly important because of the four-fold nuclear reactor development at the coast of Barakah. In Emirati cities such as Abu Dhabi and Dubai, it is also important to identify key issues such as formal training, which will improve the competence of employees in the energy sector and their ability to react in a more coherent manner during a disaster event. The UAE must act in a proactive manner and must identify any risks and vulnerabilities of energy sector for future resilience.

\section{Research Methodology}

This study followed case study research strategy and multiple case studies; three electricity generating power plant facilities- one in Abu Dhabi, one in Dubai and one in Sharjah were selected. Three power plants were selected based on the strategic importance of the facility; in terms of number of customers and significant business and urban areas the plant serves. These covered a substantial proportion, around 65\% (Al Farra and Abu-Jijleh, 2012), of national, domestic and industrial energy users. The primary data collection of this study involved a combination of a questionnaire survey and semistructured face-to-face interviews, in order to explore vulnerabilities of Emirati energy sector and examine barriers. The language used was the official language of the UAE, Arabic. Main purpose of the questionnaire survey was to explore and rank vulnerabilities of Emirati energy sector and perceived barriers. The questionnaire contained a set of eight questions with various sub-sections. The respondents were given a scale of 1 to 10 for close-ended questions with which to make their choices. In addition, "yes/no" answer options and a few open-ended questions were used. One hundred questionnaires were distributed, of which 42 were answered- 20 from Abu Dhabi, 15 from Dubai and 7 from Sharjah. Although the number of responses received from Sharjah was very low, as interviews were carried out to corroborate questionnaire survey findings from Sharjah, it was decided to include them within the analysis. All questionnaire participants were energy sector professionals and most aged between 30-40. The individuals were selected based on their position and willingness to be 
involved in the study. The average experience of respondents was about 5.2 years and Figure 1 illustrates the work position of the respondents- all belong to either the operational or technical area. Overall, most participants (81\%) were either foremen or electrical technicians/engineers.

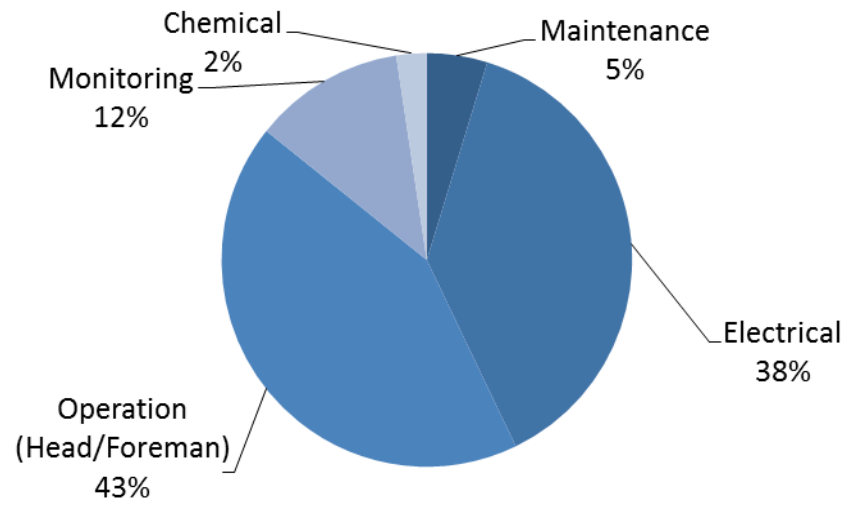

Figure $i$ : Work position of the questionnaire respondents

The semi-structured interviews were undertaken with the respective management staff of each case study power plant facility, who had sufficient knowledge of the facility operations. Respondents were shown questionnaire findings on vulnerability of Emirati energy sector and barriers, and asked to explain reasons and their views. Interview findings were used to corroborate questionnaire survey findings using open-ended questions. In total 9 interviews, 3 from each case study, were conducted among managers employed in different professions such as operational and project management as illustrated in Table 1. The experience of interview respondents varied between 7 to 21 years.

Table i: Profile of Interviewees

\begin{tabular}{|c|c|c|c|c|}
\hline Interviewee & Gender & Position & $\begin{array}{c}\text { Experience } \\
\text { (years) }\end{array}$ & Location \\
\hline 1 & Male & Head of department & 10 & Abu Dhabi \\
\hline 2 & Male & Assistant manager & 12 & Abu Dhabi \\
\hline 3 & Female & $\begin{array}{c}\text { Head of planning } \\
\text { department }\end{array}$ & 7 & Abu Dhabi \\
\hline 4 & Male & Assistant manager & 8 & Dubai \\
\hline 5 & Female & Head of department & 10 & Dubai \\
\hline 6 & Female & Director of operations & 21 & Dubai \\
\hline 7 & Male & Head of department & 13 & Sharjah \\
\hline 8 & Male & Project manager & 9 & Sharjah \\
\hline 9 & Female & Assistant manager & 7 & Sharjah \\
\hline
\end{tabular}


Both the questionnaire survey and interviews contained research questions targeting the preparation and vulnerability of Emirati energy sector for natural and man-made hazards, and potential barriers to overcome identified vulnerabilities. Data analysis included: processing both quantitative and qualitative data in software applications such as MS Excel and SPSS, generating descriptive statistical analysis, and identifying coding and themes based on content analysis. Succeeding section presents findings from both the questionnaires survey and semi-structured interviews on Emirati Energy Sector.

\section{RESULTS}

\section{Vulnerabilities of the Emirati Energy Sector}

Study classified the energy sector into its constituting components- Eclectic, Oil and Gas and asked respondents to identify which of them is the most vulnerable sector. As illustrated in Figure 2, Abu Dhabi and Dubai considered fuel exploration and supply (oil, gas) as the most vulnerable.

Respondents from Sharjah had a different view to other two cities, which is potentially due to its less modern facilities and damages to power generation facilities as a result of recent flooding events. However, all questionnaire respondents attributed high risk to the followings:

- Mechanical or electrical risk (up to $80 \%$ of respondents)- which is related to the complexity of the equipment and techniques, high voltage, probability of failure etc.

- Chemical risk (up to $60 \%$ )- mainly associated with the use of substances, flammability and the risk of leakages.

- Explosions (up to 50\%)

- Oceanic exploration risk (up to 27\%)- as operations in the sea are more complicated and riskier than their terrestrial counterparts

- Social risk (up to 20\%)- due to the potential of the energy sector forming a terrorist target.

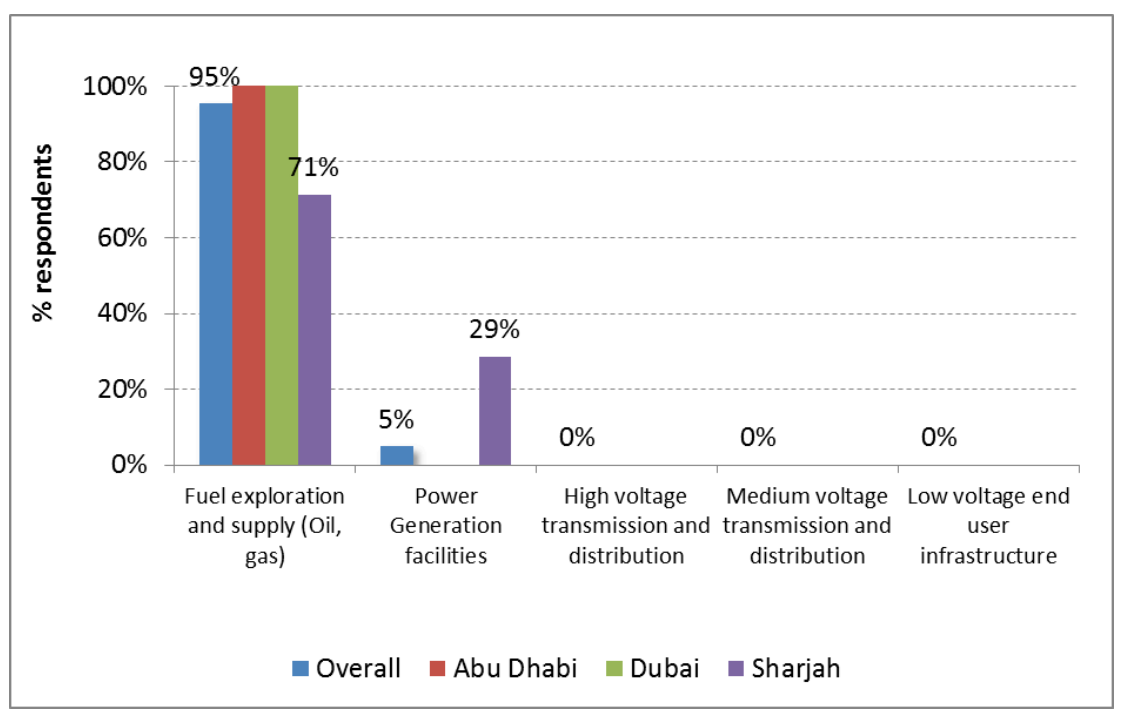


For semi-structured interview respondents, "all infrastructural components are important given that they work collectively and none of them work in isolation". However, the most critical and vulnerable components are the generating stations and specifically the larger generating equipment. Abu Dhabi holds a particular strategic importance given that its generating system provides energy not just locally but for Dubai and Sharjah. One of the questions in questionnaire survey examined the vulnerability of the Emirati energy sector to natural and man-made hazards. Overall results indicated terrorism, atmospheric and tectonic hazards as the three main risks of vulnerability within Emirati energy sector, as illustrated in Figure 3.

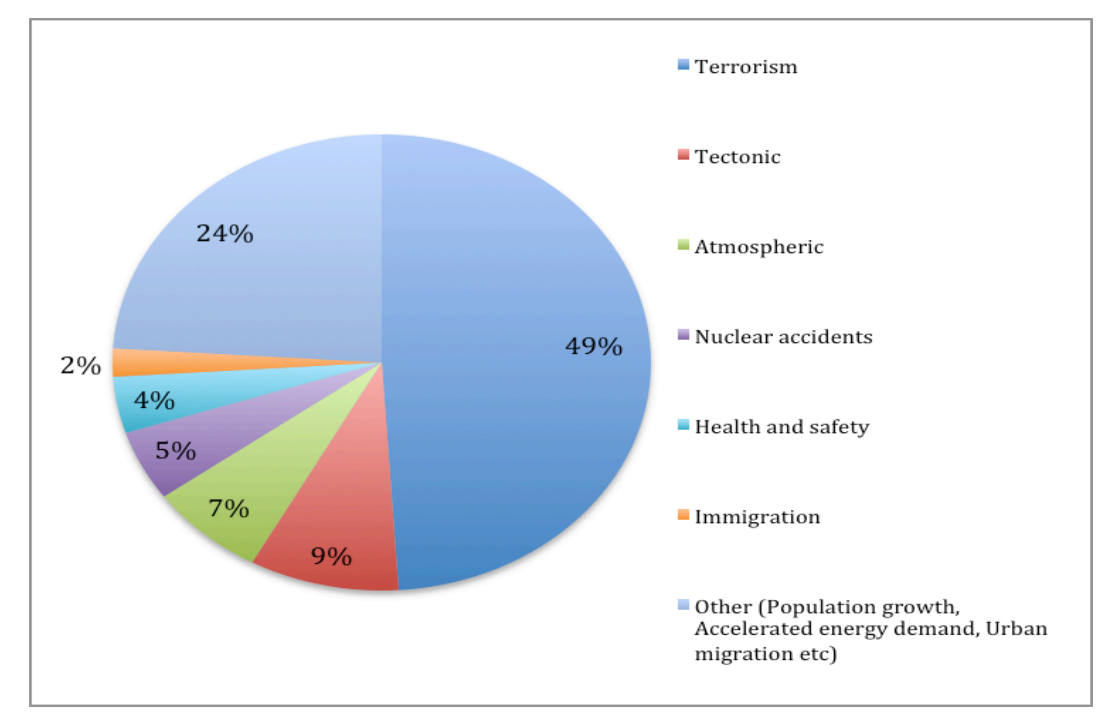

Figure iii: Vulnerabilities of Emirati energy sector

Terrorism is thought to be the greatest vulnerability with every single respondent from Abu Dhabi and Dubai choosing it. Overall almost half of the questionnaire respondents, regardless of the location, selected "terrorism" as a threat. This result is similar to findings of research by Alomash and $\mathrm{Al}$ Khattar (2013), which identified terrorism as the biggest threat to the stability of UAE. Interview respondents agreed on three main risks of vulnerability. In terms of terrorism risk to energy sector, they thought that it probably stems from regional uprising since the Arab Spring 2011, including recent terrorist activities in the region and nuclear power associated issues. In Sharjah, the greatest vulnerability was considered to be atmospheric, maybe due to the recent flooding events. The "other" category included primarily the risk of population growth and climate change as the major concerns.

\section{Perceived Barriers to Enhance Resilience}

As part of the questionnaire survey, any existing or potential barriers that may prevent the energy sector from dealing with the vulnerabilities identified were examined. These are illustrated in Figure 4. Overall, the most significant barrier that was indicated by questionnaire survey respondents was the 'lack of or absence of national government legislation'. All respondents from Abu Dhabi and Dubai 
indicated that 'public awareness and education' as the biggest barrier. In Sharjah, this figure was the lowest of all at 14\%. In fact the biggest barrier for Sharjah was related to 'lack of government legislation and initiatives' on disaster management within energy sector. For the open-ended question, participants identified the followings in addition to those listed above:

- Disaster management training in the energy sector remains to be addressed ( $71 \%$ of the respondents)

- Staff competences, especially through education, to support the understanding of climate change and its related disasters $(31 \%)$

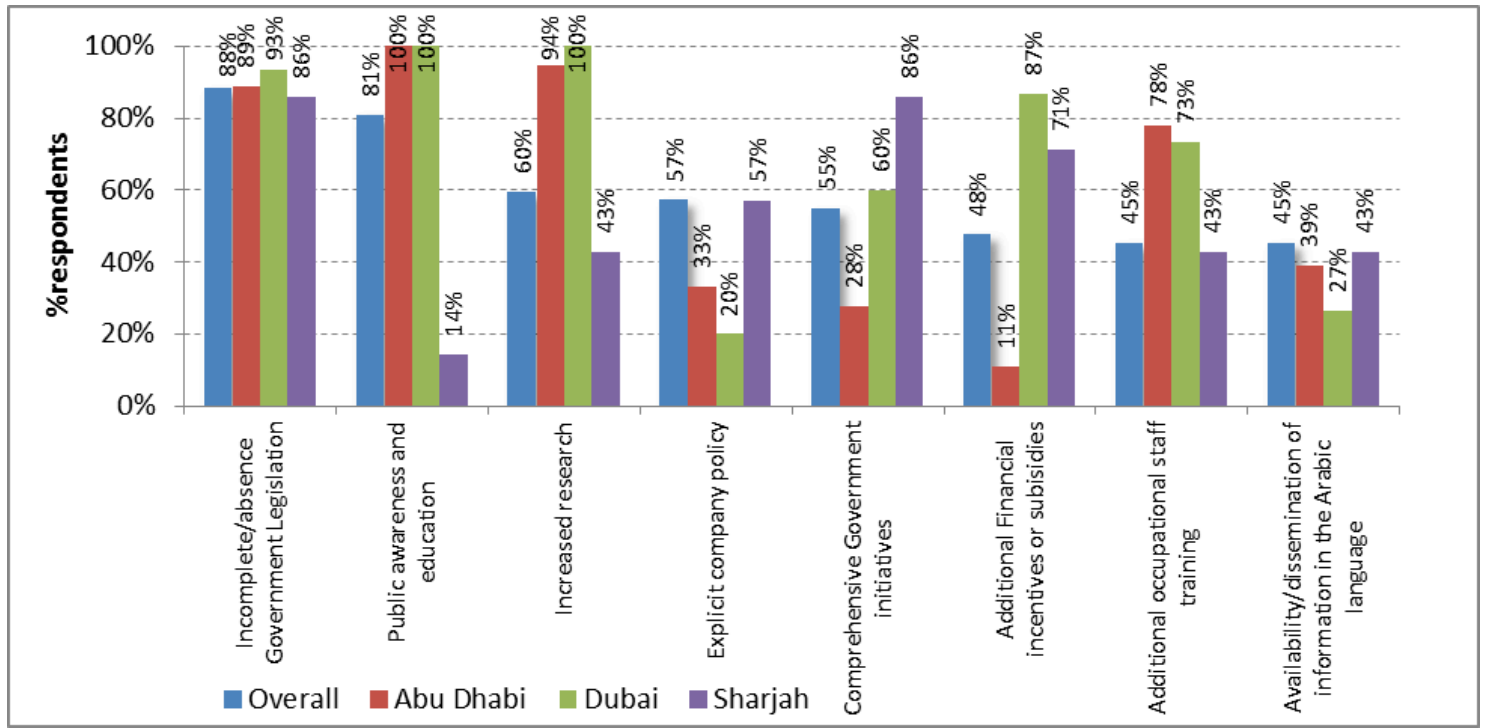

Figure iv: Potential barriers of Emirati energy sector

In order to overcome barriers identified, questionnaire survey respondents argued that it is necessary to:

- Undertake verification simulations to assess the level of personnel preparation, organisational structure in disaster response and resource capacity installed (31\%)

- Develop a better planning stage for disaster preparation (26\%)

- Achieve greater awareness, which means to give more priority to disaster preparedness $(23 \%)$

- Improve the human resource management policies in companies, such as safe working practices $(6 \%)$

- Set more regulations in line with sound disaster management practices (3\%)

It is notable that the majority of these responses are aimed at improving human resource management within Emirati energy sector such as awareness, training, practices etc. For semi-structured interview respondents from the management team, the greatest barriers to address vulnerability and disaster risk in the energy sector were very much same as those identified by the operational workers as part of the questionnaire survey. Most, if not all, were related to education, training and increasing general 
awareness of energy personnel operating at all levels. It was stated that "policy, specifically relating to education, must be improved. This will support disaster mitigation generally and increase resilience". Interview respondents argued that the barriers identified apply to the Emirati energy sector in general, not just for the case studies represented in this study. Also they thought that responsibilities to address barriers should be shared and coordinated between all actors- government, public and private sectors. Further to overcome any kind of barrier, learning from relevant and valuable international and regional experiences is considered highly important by interview respondents. There was also a call to "share energy sector experiences, within the government ministries at national level". In fact interview respondents argued that government legislations should facilitate the sharing of experiences within whole Emirati energy sector.

\section{DISCUSSION}

Study selected workers who are directly affected by hazards, and experienced failures and disastrous events in Emirati energy sector as the respondents for both questionnaire survey and semi-structured interviews. The literature review and the responses to the questionnaire survey revealed key potential hazards that lead to vulnerability in Emirati energy sector and they included tectonic activities such as earthquakes and tsunamis; atmospheric activities such as Shamal and flooding; and a few man-made disasters such as war and terrorism. War, despite not having been specifically listed as a possible answer, questionnaire survey respondents identified it within other category. Further, 'terrorism' was identified as the greatest risk of vulnerability. This is, in some respects, unusual because of the lack of political instability in the UAE. However, there have been regional issues such as historical problems with Iran and the political climate in Arab region following the Arab Spring.

The main barriers to resilience in the energy sector included 'absence of national government legislation' and 'public awareness and education'. In addition, respondents perceived lack of research in terms of sharing good practices across energy sector as a barrier to enhance resilience. Most respondents in their questionnaire and all those management staff interviewed stated that education and training as the most important intervention needed when it comes to building resilience in Emirati energy sector. Considering the importance given to education/ training by respondents, relevant courses should be designed to develop skills and awareness using effective and participatory methodologies within energy sector. All these issues are proactive responses to disaster management and resilience in Emirati energy sector. Given the long-term nature of training and development programmes, it is in the Emirati energy sector's best interest to launch it as soon as practicably possible. Before any launch however, the Ministry of Energy needs to ascertain in greater detail the exact type and level of disaster preparation training, education and awareness. Initiatives such as training and education are also proposed to go beyond those individuals working in the energy sector and to reach schoolchildren and university students. The level of training and general awareness was seen as having great importance, contributing significantly to the ability to make the right strategic decisions for improved resilience. 


\section{CONCLUSION}

Developing and emerging nations are particularly vulnerable to natural hazards and ill prepared for man-made threats. For the UAE specifically, the range of disasters that the nation could face is significant. Given the numerous types of hazards that could impact the UAE, the energy sector in particular must reduce vulnerability and build resilience for any potential disaster. This study revealed main vulnerabilities of Emirati energy sector, existing or potential barriers that may prevent the energy sector from dealing with the vulnerabilities identified and possible ways to overcome those barriers. Results indicated terrorism, atmospheric and tectonic hazards as the three main risks of vulnerability within Emirati energy sector, whereas 'lack of or absence of national government legislation' and 'awareness and education' are revealed as the main barriers. It is argued that barriers identified by this study can be applicable to the Emirati energy sector in general, not just for the case studies selected. A recent report published by NPC (2014) on preparedness of energy sector in US identified similar issues on awareness. A number of actions are recommended to address barriers including: Strengthening policies for disaster management and incentivising the right type of investment opportunities to trigger various financially and technically viable solutions; Increase public awareness relating to disasters and hazards that may have a detrimental effect on the energy sector; Improving human resource management within Emirati energy sector through better awareness, training and practices; and Generating networks of learning which facilitate the exchange of best practices within energy sector. This study helped directing the Emirati energy sector into a more resilient and sustainable facility.

\section{References}

Al Ghasyah, H, Duncan, A and Chester, D., (2010), Chapter 5 United Arab Emirates: Disaster Management with Regard to Rapid Onset Natural Disasters, Safari

Al-Amri, A., (2005), Seismic source zones of the Arabian Peninsula and adjacent countries, Gulf Seismic Forum, UAE University, Al-Ain, UAE

Al Farra, H and Abu-Hijleh, B., (2012), The potential role of nuclear energy in mitigating CO2 emissions in the United Arab Emirates, Energy Policy, Vol42 pp 272-285

Al Khaili, K and Pathirage, C., (2014), A Critical Review On Disaster Preparedness And Management of The Emirati Energy Sector, Revista EAN No77, pp 104-121

Al Kindi, M., (2007), UAE gears up to tackle any potential disaster UAE, http://www.uaeinteract.com/docs/UAE_gears_up_to_tackle_any_potential_disaster/25446.htm [accessed 23/05/2007]

Alomash, A and Al Khattar., (2013), Uncomfortable Freedom: The Impact of Terrorism in the Arab World [Within] Romaniuk, S New Wars: Terrorism and Security of the State Dorrance Publishing, pp 179-199 
Atmanand, R., (2003), Insurance and Disaster Management: The Indian Context, Disaster Prevention and Management, Vol12(4), pp. 286-304

Ciottone, G., (2006), Disaster medicine, Health Sciences, Elsevier

Dalli, E and Wilcox, G., (2006), Punching Above Its Weight, GB Reports

Dougherty, W, Fencl, A, Elasha, B, Swartz, C, Yates, D, Fisher, J and Klein, R., (2009), Climate Change Impacts, Vulnerability and Adaptation, Stockholm Environment Institute

EUAEW - Embassy of the United Arab Emirates in Washington DC, (2011), Energy in the UAE http://www.uae-embassy.org/uae/energy [Accessed 27/12/11]

Fitzgerald, G and Fitzgerald, N., (2005), Assessing Community Resilience to Wildfires: Concepts \&

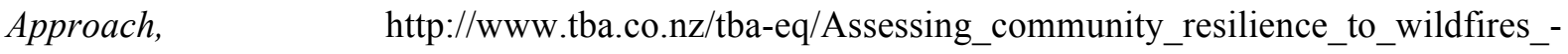
_fitzgerald_2005.pdf [Accessed November 2011]

Frumkin, H., (2010), Environmental Health: From Global to Local, John Wiley and Sons

González-Diez, A, Fernández-Maroto, G, Doughty. M, Remondo, J and Bruschi, E., (2012), Advances in Spanish Geomorphology 2010-2012, Actos de la XII Reunión Nacional de Geomorfología, 17-20 Septiembre 2012, Universidad de Cantabria

Gulf News, (2013), Construction of the UAE's second nuclear power plant under way, Gulf News 28/5/13, http:/gulfnews.com/news/gulf/uae/general/construction-of-the-uae-s-second-nuclear-powerplant-under-way-1.1189598 [Accessed June 2013]

Hafez, R and Halim, A., (2007), Utilisation of Advanced Engineering Technologies to Enhance the Protection of Critical Energy Infrastructure in the Gulf Region, Critical Energy Infrastructure Protection Policy Research Series, No. 3, Canadian Centre of Intelligence and Security Studies

Hays, W., (2013), Strategies for Becoming Disaster Resilient During 2013, Part II Global Alliance for Disaster Reduction, University of North Carolina, USA http://www.pitt.edu/ super1/collections/collection52.htm [Accessed July 2013]

Katzman, K., (2012), The United Arab Emirates (UAE), Issues for U.S. Policy Congressional Research Service http://www.fas.org/sgp/crs/mideast/RS21852.pdf [Accessed October 2012]

Kazmi, A., (2014), Chilly weather to persist over the weekend in UAE, Gulf News 6/2/2014 http:/gulfnews.com/news/gulf/uae/weather/chilly-weather-to-persist-over-the-weekend-in-uae1.1287371 [Accessed February 2014]

Levinson, J and Granot, H., (2002),Transportation Disaster Response Handbook, Elsevier

McEntire, D., (2010), Addressing Vulnerability through an Integrated Approach, International Journal of Disaster Resilience in the Built Environment, Vol1(1), pp. 50-64. 
Moe, T. L., Gehbauer, F., Sentz, S. \& Mueller, M., (2007), Balanced Scorecard for Natural Disaster Management Projects, Disaster Prevention and Management, Vol16(5), pp. 785-806.

Nambier, S., (2010), UAE energy sector contracts triple to $\$ 8.8 b n$, Emirates 24/7 14/6/10 http://www.emirates247.com/eb247/companies-markets/construction/uae-energy-sector-contractstriple-to-8-8bn-2010-06-14-1.255051 [Accessed 27/12/11]

National Petroleum Council, (2014), Enhancing Emergency Preparedness for Natural Disasters: Government and Oil and Natural Gas Industry Actions to Prepare, Respond, and Recover, http://www.npc.org/reports/npc_emprep_report_2014-12-18.pdf [Accessed December 2015]

OSAC, (2013), United Arab Emirates 2013 Crime and Safety Report: Abu Dhabi, US Bureau of Security https://www.osac.gov/Pages/ContentReportDetails.aspx?cid=13886 [Accessed June 2013]

RICS, (2009), The Built Environment Professions in Disaster Risk Reduction and Response, London.

Shanableh, A, Barakat, S and Malkawi, A., (2005), A Framework for Comparative Risk Assessment of Earthquakes Consequences in the United Arab Emirates, Disaster Reduction on Coasts Conference, Monash University, Melbourne, Australia, 14-16 November 2005

UNISDR, (2012), The Economic and Human Impact of Disasters in the Last 12 years, http://www.unisdr.org/files/25831_20120318disaster20002011v3.pdf [Accessed July 2013]

US EIA, (2013), EIA projects world energy consumption will increase $56 \%$ by 2040, http://www.eia.gov/todayinenergy/detail.cfm?id=12251 [Accessed January 2015]

Warfield, C., (2004), The Disaster Management Cycle, [online] Available at: $<$ http://www.gdrc.org/uem/disasters/1-dm_cycle.html> [Accessed 02/12/2014].

WAM, (2014), UAE Cabinet approves list of designated terrorist organisations, groups http://www.wam.ae/en/news/emirates-international/1395272478814.html [Accessed December 2014]

WHO-World Health Organisation, (2014), Urban Population Growth, http://www.who.int/gho/urban_health/situation_trends/urban_population_growth_text/en/ [Accessed January 2015] 